\title{
Holmium Laser Ureteroscopy in the Treatment of the Upper Urinary Tract Stones: Concerning 54 Cases in the Surgical Department of the Saint Camille Hospital of Ouagadougou (Burkina Faso)
}

\section{Clotaire Alexis Marie Kiemdiba Donega Yaméogo ${ }^{*}$, Bienvenu Ky ${ }^{1}$, Adama Ouattara ${ }^{2}$, Brahima Kirakoya1, Fasnewendé Aristide Kaboré ${ }^{1}$}

\author{
${ }^{1}$ Department of Urology, Yalgado Ouédraogo Teaching Hospital, Ouagadougou, Burkina Faso \\ ${ }^{2}$ Department of Urology, Sanon Souro Teaching Hospital, Bobo Dioulasso, Burkina Faso \\ Email: *yameogoclotaire@yahoo.fr
}

How to cite this paper: Yaméogo, C.A.M.K.D., Ky, B., Ouattara, A., Kirakoya, B. and Kaboré, F.A. (2020) Holmium Laser Ureteroscopy in the Treatment of the Upper Urinary Tract Stones: Concerning 54 Cases in the Surgical Department of the Saint Camille Hospital of Ouagadougou (Burkina Faso). Open Journal of Urology, $10,17-24$

https://doi.org/10.4236/oju.2020.102003

Received: November 8, 2019

Accepted: December 27, 2019

Published: December 30, 2019

Copyright $\odot 2020$ by author(s) and Scientific Research Publishing Inc. This work is licensed under the Creative Commons Attribution International License (CC BY 4.0).

http://creativecommons.org/licenses/by/4.0/

\begin{abstract}
The treatment of urinary stones uses a varied therapeutic arsenal. Nowadays the mini-invasive techniques are the most used. We report our first experience on the results of flexible and semi-rigid ureteroscopy in the treatment of the upper urinary tract stones. Materials and Methods: A 20-month prospective study on flexible laser ureteroscopy was conducted at the Saint Camille Hospital of Ouagadougou. The inclusion criteria were for patients who had given informed consent and the presence of an unilateral obstructive upper urinary tract stone with an indication of surgical management. Results: 54 patients were treated with Holmium laser photo vaporization between January 2018 and August 2019. The average age of patients was $37.74 \pm 17$ years (11- 83 years). The men were predominant at $55.56 \%$, or a sex-ratio of 1.25. The average size of stones of $17.55 \mathrm{~mm} \pm 4.16 \mathrm{~mm}(11 \mathrm{~mm}$ to $25 \mathrm{~mm})$ with pyelic, ureteral and calyceal localization in respectively $42.6 \%, 33.3 \%$ and $24.1 \%$ of cases. The average duration of the interventions was $77.92 \pm 43.57 \mathrm{~min}$ utes (11 to 180 minutes). We used drainage in $90.91 \%$ of the cases. The average duration of hospitalization was $1.2 \pm 0.73$ days with extremes ranging from one day to 6 days. The vaporization without residual fragment which is a success was $78.46 \%$. Conclusion: Laser ureteroscopy is a newly used method at the Saint Camille hospital. The achievement of good results and its low morbidity encourage us to promote its extension and its use in sub-Saharan African hospitals.
\end{abstract}




\section{Keywords}

Flexible Ureteroscopy, Laser, Stone, Burkina Faso

\section{Introduction}

Urinary lithiasis is the presence in the urinary tract (renal cavities, ureters, bladder) of crystalline, mineral, organic or medical concretions [1].

The urinary lithiasis, a highly recurrent pathology, is responsible for several hospitalizations in urology services and can be responsible for many renal functional consequences [2] [3].

The prevalence in western countries is now estimated at around 10\% [1]. The risk of developing urinary lithiasis is estimated to be from $5 \%$ to $9 \%$ in Europe, $12 \%$ in Canada and from $13 \%$ to $15 \%$ in the United States of America (USA) [4]. In Burkina Faso, the hospital prevalence of urinary lithiasis was 12.52\% [5].

The treatment of urinary stones uses a varied therapeutic arsenal. In our context of resource-constrained countries, treatment remains predominantly dominated by open-pit/open-air surgery. Nowadays the mini-invasive techniques are the most used.

In the treatment of upper urinary tract stones, Laser Ureteroscopy is an effective and safe method. The therapeutic choice of upper urinary tract stones depends on the location and size of the stones. Laser Ureteroscopy appears to be the appropriate treatment for stones less than $20 \mathrm{~mm}$ [6]. Its low morbidity urges some urologists to prefer several sessions of the Laser Ureteroscopy to a Percutaneous Nephrolithotomy when the size of stones exceeds $20 \mathrm{~mm}$ [7]. In our poor countries, its accessibility is limited by its high cost and the fragility of the equipment. We report our first experience on the results of flexible and semi-rigid ureteroscopy in the treatment of the upper urinary tract stones.

\section{Materials and Methods}

A prospective study was conducted between January 2018 and August 2019 (20 months) within the surgical department of the hospital Saint Camille de Ouagadougou. Our study involved 54 patients with unilateral stone. Patient management was done in two stages. All patients received an intervention and those with a residual stone size of more than $3 \mathrm{~mm}$ benefited from a second operation. The inclusion criteria were for patients who had given informed consent and the presence of an obstructive stone of the upper urinary tract with indication of surgical management.

The procedure was performed under general anesthesia after checking the sterility of the urine. The administration of prophylactic antibiotic therapy based on ceftriaxone $2 \mathrm{~g}$ and gentamycin $160 \mathrm{mg}$ was systematic after the induction of anesthesia.

Using a cystoscope, we scan the bladder and locate the ureteral meatus, then 
we set up a guide wire in the renal cavities. A second hydrophilic safety guide wire is also positioned in the renal cavities, then we progress to the stone bed with the semi-rigid ureteroscope on the rail of the two hydrophilic guide wires.

The semi-rigid urethroscope is withdrawn keeping the two guide wires in place. The flexible urethra is placed in the urinary cavities until the stone using the second guide wire leaving the safety guide wire in place. The laser fibres used were 272 or $550 \mu$ depending on the size of the stone. A simple irrigation flow at the pressure of $100 \mathrm{~cm}$ of water combined with a hand pump was used to improve irrigation. Most often, the laser has been configured according to the following programmes: the energy of $1.2 \mathrm{~J}$ and the frequency of $15 \mathrm{~Hz}$. After complete spraying or obtaining fragments of less than $3 \mathrm{~mm}$, a drainage of the excretory tract by ureteral or double J catheter was proposed. A double J catheter was systematically left in place in patients with incomplete fragmentation of the stones, or with a single kidney and or session longer than 90 minutes and or ureter dilation. A bladder catheter was left in place for 24 hours.

The patients were re-assessed after four weeks by an X-ray of the abdomen, renal ultrasound or CT scan. In the case of residual fragments greater than $3 \mathrm{~mm}$ in diameter, a second ureteroscopy time was rescheduled. The success was defined by the complete disappearance of the stone or the persistence of residual fragments of less than $3 \mathrm{~mm}$. patients were advised to hyper hydration to facilitate the evacuation of the fragments. the data collected included patient characteristics (age, sex, reason for consultation, size and location of calculation), surgical and post-operative data (response time, incidents, drainage, duration of hospitalization) and follow-up (control imaging and presence of residual fragments). The data were entered and analysed using the epi info 7 software.

\section{Results}

\subsection{Characteristics of the Study Population}

54 patients were treated by stone photo vaporization with Holmium laser between January 2018 and August 2019.

The average age of patients was $37.74 \pm 17$ years old (11 - 83 years old).

The men were predominant at $55.56 \%, 30$ men and 24 women with a sex-ratio of 1.25 .

Lumbar pain with simple nephritic colic type was the reason for consultation in all patients.

\subsection{Characteristics of the Stones}

The main locations of the lithiasis on the urinary shaft were the renal pelvis, the ureter and the calyxes in 23,18 and 13 of the cases respectively (Figure 1).

Several types of lithiasis were found during the ureteronephroscopy sessions with different colors but their physicochemical nature was not specified (Figure 2).

The average size of the stones from $17.55 \mathrm{~mm} \pm 4.16 \mathrm{~mm}$ (11 mm to $25 \mathrm{~mm})$. 
All patients benefited from a Uro TDM that objectified hyper dense stones whose density was not evaluated.

\subsection{Operative Management}

The surgery involved 54 unilateral stones. A total of 65 interventions were performed, with a first serial of 54 and a second of 11 repeated interventions.

The average duration of interventions was $77.92 \pm 43.57$ minutes with extremes of 11 to 180 minutes.

We used drainage in $90.91 \%$ of cases (Table 1 ).

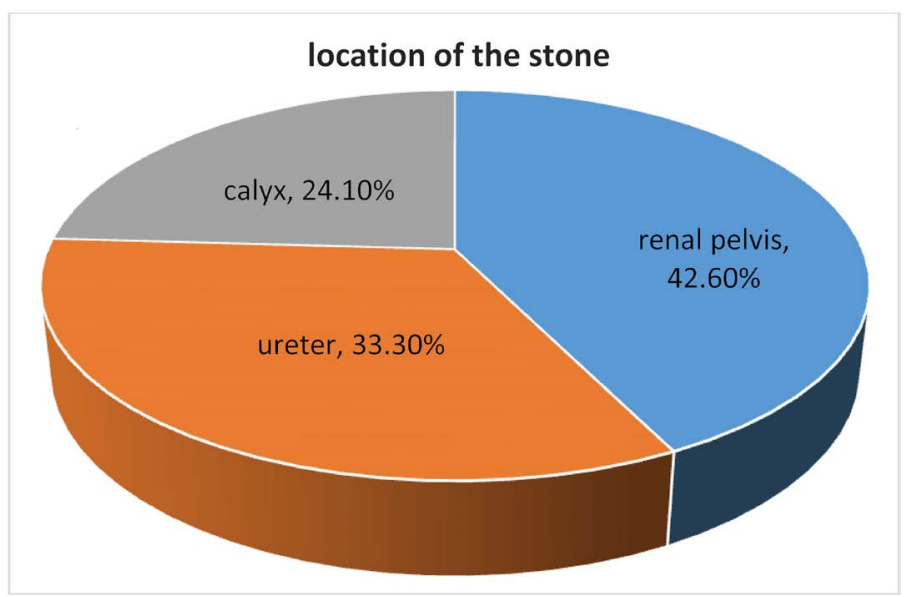

Figure 1. Distribution of patients by location of the stone.

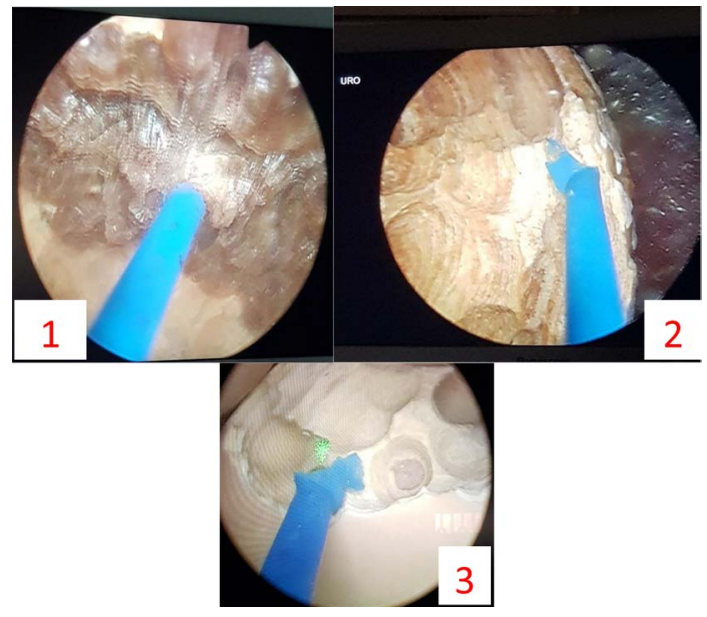

Figure 2. Nephrolithiasis found during Holmium laser ureteroscopic surgery sessions.

Table 1. Type of drainage.

\begin{tabular}{ccc}
\hline Drainage & Frequency (n) & Percentage (\%) \\
\hline Ureteral Catheter & 11 & 20 \\
Double J Catheter & 38 & 70.91 \\
Without drainage & 5 & 9.09 \\
Total & 54 & 100 \\
\hline
\end{tabular}


The average drainage duration was one day for ureteral catheter and four weeks for double J catheter.

The average duration of hospitalization was $1.2 \pm 0.73$ days with extremes ranging from one day to 6 days.

All patients benefited from an X-ray and Ultrasound scan.

The overall success rate was $78.46 \%$ (Table 2). We noted 3 cases of residual stones in the inferior calyx around $7 \mathrm{~mm}$ size.

Any complication was noted.

\section{Discussion}

The limits of our study are the small sample size, the patient follow-up time and the absence of stone density. Despite these limits, the following comments or discussions may be made.

The lithiasis of developing countries was considered, until recently, as a particular lithiasis affecting mainly the young boy under five years of age and characterized by stones localized preferentially in the bladder [1]. The average age of patients in our series was $37.74 \pm 17$ years. Kaboré in Burkina regained a median age of 35 years [5]. This result was similar to recent literature data presenting urinary lithiasic disease as a condition of the young subject between the third and fourth decades [1].

As for the duration the intervention, it depends on the parameters of the stones (size, location), the quality of the ureteroscope for a good visibility, the right choice of laser parameters according to the nature of the stone but also and above all, the operator's experience.

Essodina Padja and collaborators [6] found an average intervention time of 73 $\min \pm 25 \mathrm{~min}$ for an average size of $13.78 \mathrm{~mm} \pm 5 \mathrm{~mm}$. In our study, the average duration of the intervention was $77.92 \pm 43.57$ minutes. The durations reported in the literature are extremely variable but it usually takes $60 \mathrm{~min}$ to fragment a $10 \mathrm{~mm}$ stone [8].

Concerning the post-operative drainage, there is no consensus on the omission or the type of drainage to be carried out in post-operative. The data in favour of post-operative drainage are: an impacted stone, a long intervention time, lesion of the ureteral mucosa during the intervention, presence of fragments after the intervention, the operator's assessment and tendency.

In the literature the tendency is rather on short-term drainage by ureteral catheter or endoprosthesis [9].

In our series, we used catheter in $90.91 \%$ of cases.

Table 2. Free stone percentage.

\begin{tabular}{cccc}
\hline Free Stones & Intervention $(\mathbf{n})$ & Frequency (n) & Percentage (\%) \\
\hline First serial & 54 & 43 & 79.62 \\
Second serial & 11 & 8 & 72.72 \\
Total & 65 & 51 & 78.46 \\
\hline
\end{tabular}


Laser ureteroscopy is a modern approach to the treatment of renal and ureteral stones. Because of its endoscopic nature and because the lithotrity takes place by vaporisation of contact holmium Laser, it responds to the treatment of all types of stone [10].

The indications of first-line laser ureteroscopy in the treatment of the upper urinary tract stones are well established by the lithiasis committee of the French Urological Association and other scholar companies [8].

Several authors have reported through their experiments the efficiency of Laser ureteroscopy in the treatment of stones and particularly stones less than 20 $\mathrm{mm}$ in diameter.

E. Lechevalier and Conort P. [11] [12] report an overall success rate for kidney stones between $65 \%$ and $85 \%$ and for ureteral stones between $75 \%$ and $90 \%$. In P-O. Faïs's study, the success rate for upper calyxes and the renal pelvis are from $60 \%$ to $100 \%$, and from $60 \%$ to $80 \%$ for lower calyxes [9].

Concerning M.A. Ben Saddik and his collaborators [7] who were interested in stones of 2 to $3 \mathrm{~cm}$, their overall success rate was $63.1 ; 89.3 \%$ and $97.1 \%$ respectively after one, two and three laser flexible Ureteroscopy sessions. B. Fall and collaborators [13] report a global success rate of $71.7 \%$ in their series.

Essodina Padja and collaborators [6], the overall success rate was $78.91 \%$. We have got an overall success rate of $78.46 \%$ for all stones. These results are comparable to those in the literature but it should be noted that the maximum size of the stones in our study was $25 \mathrm{~mm}$. The factors determining the achievement of a no residual fragment were the size of the renal stone and the operator's experience.

We did not find any complication but some authors noted some complications.

A low rate of morbidity is associated with laser ureteroscopy in the treatment of kidney and ureteral stones. Recent studies report few major complications [14]. The literature reports an overall morbidity of ureteroscopy of 5\% - 10\% [10]. The risk of major complications (avulsion, perforation) is $1 \%$. The risk of late complications is due to stenosis and is of the order of $1 \%$. The risk of febrile infection after ureteroscopy is $2 \%-18 \%$ [10]. Essodina Padja noted an overall complication rate of $14.46 \%$ and a single case (0.6\%) of ureteral stenosis [6]. These low rates of complication support the idea that laser ureteroscopy is a grafted method with very little morbidity.

\section{Conclusions}

Laser ureteroscopy is a newly used method at Saint Camille Hospital. Our study, like those already published, shows that laser ureteroscopy is an effective and safe method in the treatment of kidney and ureteral stones.

The achievement of good results and its low morbidity encourage us to promote its extension and its use in other hospitals.

\section{Consent}

Consents of the patients were obtained before publication of this article. 


\section{Conflicts of Interest}

The authors declare no conflicts of interest regarding the publication of this paper.

\section{References}

[1] Daudon, M. (2005) Epidemiology of Nephrolithiasis in France. Annales d Urologie, 39, 209-231. https://doi.org/10.1016/j.anuro.2005.09.007

[2] Raynal, G., Merlet, B. and Traxer, O. (2011) In-Hospital Stays for Urolithiasis: Analysis of French National Data. Progrès en Urologie, 21, 459-462. https://doi.org/10.1016/j.purol.2011.02.002

[3] Saussine, C., Lechevallier, E. and Traxer, O. (2008) Urolithiasis: Cost-Effectiveness. Progrès en Urologie, 18, 875-877. https://doi.org/10.1016/j.purol.2008.09.004

[4] López, M. and Hoppe, B. (2010) History, Epidemiology and Regional Diversities of Urolithiasis. Pediatric Nephrology, 25, 49-59. https://doi.org/10.1007/s00467-008-0960-5

[5] Kaboré, F.A., Kambou, T., Zango, B., Ouattara, A., Simporé, M., Lougué/Sorgho, C., Lechevalier, E. and Karsenty, G. (2013) Epidemiology of a Cohort of 450 Urolithiasis at the Yalgado Ouédraogo University Hospital of Ouagadougou (Burkina Faso). Progrès en Urologie, 23, 971-976. https://doi.org/10.1016/j.purol.2013.04.014

[6] Padja, E., Ibarra, V.A., Lmezguidi, K., Janane, A., Ghadouane, M., Ameur, A. and Abbar, M. (2015) Urétéroscopie souple laser dans le traitement des calculs du haut appareil urinaire: Résultats à propos de 166 interventions. Pan African Medical Journal, 22, 13. https://doi.org/10.11604/pamj.2015.22.13.7591

[7] Ben Saddik, M.A., Al-Qahtani Sejiny, S., Ndoye, M. et al. (2011) Flexible Ureteroscopy in the Treatment of Kidney Stone between 2 and $3 \mathrm{~cm}$. Progrès en Urologie, 21, 327-332. https://doi.org/10.1016/j.purol.2010.07.012

[8] Carpentier, X., Meria, P., Bensalah, K., Chabannes, E., Estrade, V., Denis, E., Yonneau, L., Mozer, P. and Hadjadj, H.A. (2014) Update for the Management of Kidney Stones in 2013. Stone Group Comity of the French Association of Urology. Progrès en Urologie, 24, 319-326. https://doi.org/10.1016/j.purol.2013.09.029

[9] Faïs, P.-O., Albert, T. and Gaillet, S. (2011) Flexible Ureteroscopy with Laser for Upper Urinary Tract Stone. Progrès en Urologie, 21, 811-815. https://doi.org/10.1016/j.purol.2011.10.001

[10] Lechevallier, E., Saussine, C. and Traxer, O. (2008) Ureteroscopy for Upper Urinary Tract Stones. Progrès en Urologie, 18, 912-916. https://doi.org/10.1016/j.purol.2008.09.022

[11] Maurin, C., Boissier, R. and Lechevallier, E. (2012) Renal Colic in Emergency Departments. Journal Européen des Urgences et de Réanimation, 24, 29-37. https://doi.org/10.1016/j.jeurea.2012.02.001

[12] Conort, P., Doré, B. and Saussine, C. (2004) Prise en charge urologique des calculs rénaux et urétéraux de l'adulte. Progrès en Urologie, 14, 1096-1102.

[13] Fall, B., Mouracade, P., Bergerat, S. and Saussine, C. (2014) Flexible Ureteroscopy and Laser Lithotripsy for Kidney and Ureter Stone: Indications, Morbidity and Outcome. Progrès en Urologie, 24, 771-776. https://doi.org/10.1016/j.purol.2014.06.007

[14] Breda, A., Ogunyemi, O., Leppert, J.T., Lam, J.S. and Schulam, P.G. (2008) Flexible 
Ureteroscopy and Laser Lithotripsy for Single Intrarenal Stones $2 \mathrm{~cm}$ or Greater-Is This the New Frontier? Journal of Urology, 179, 981-984.

https://doi.org/10.1016/j.juro.2007.10.083 